\title{
SIMULTANEOUS ESTIMATION OF PIOGLITAZONE, GLIMEPIRIDE AND GLIMEPIRIDE IMPURITIES IN COMBINATION DRUG PRODUCT BY A VALIDATED STABILITY- INDICATING RP-HPLC METHOD
}

\author{
G. NAVANEETHAN ${ }^{1}, K_{\text {KARUNAKARAN }}^{1 *}$ AND K. P. ELANGO ${ }^{2}$ \\ ${ }^{1}$ Department of Sciences, Sona College of Technology (Anna University), Salem 636 005, India. \\ ${ }^{2}$ Department of Chemistry, Gandhigram Rural Institute (Deemed University), Gandhigram 624 302, India.
}

(Received: April 5, 2011 - Accepted: June 29, 2011)

\begin{abstract}
A new, single, stability indicating RP-HPLC method has been developed and validated for the simultaneous estimation of pioglitazone, glimepiride and glimepiride impurities i.e., related compound $\mathrm{B}$ and related compound $\mathrm{C}$ from combination drug product containing pioglitazone, glimepiride and metformin $\mathrm{HCl}$. The chromatographic separation was achieved on a cyano stationary phase $(250 \mathrm{x} 4.6 \mathrm{~mm}, 5.0$ microns particles $)$ with simple mobile phase combination delivered in gradient mode at a flow rate of $0.8 \mathrm{~mL} \mathrm{~min}^{-1}$ at $230 \mathrm{~nm}$. In the developed method, the critical close eluting compound of glimepiride related compound B and related compound $\mathrm{C}$ was found more than 6.5 resolutions. This method is capable to detect glimepiride related compound $\mathrm{B}$ and related compound $\mathrm{C}$ at a level below $0.005 \%$ with respect to glimepiride sample concentration of $0.1 \mathrm{mg} \mathrm{mL}^{-1}$ for a $25 \mu \mathrm{L}$ injection volume. The proposed method was validated according to the ICH guidelines and proved suitable for routine and stability analysis of these drugs in pharmaceutical preparations.
\end{abstract}

Key word: stability indicating; peak purity; impurities; validation.

\section{INTRODUCTION}

Glimepiride is a medium-to-long acting sulfonylurea anti-diabetic drug. ${ }^{1}$ Pioglitazone is a prescription drug of the class thiazolidinedione (TZD) with hypoglycemic (antihyperglycemic, antidiabetic) action. ${ }^{2}$ Glimepiride is official in US Pharmacopoeia, ${ }^{3}$ which describes the HPLC method for the determination of either in raw material or in pharmaceutical formulations. Pioglitazone is not official in any pharmacopoeia. The literature contains several methods for the determination of glimepiride in pharmaceutical dosage forms, including liquid chromatography ${ }^{4}$ and derivative spectroscopy. ${ }^{5}$ Glimepiride related substances as well as degradation pathway methods were reported. ${ }^{6-8}$ Similarly degradation behavior of pioglitazone method and stability indicating assay method was also available. ${ }^{9-11}$ Some assay method is reported in the combination tablets. ${ }^{12-14}$

No stability indicating HPLC method has been reported yet for the simultaneous determination of glimepiride and pioglitazone in combination drug product. By seeing the glimepiride and pioglitazone degradation behavior it is essential and worth full to develop a stability indicating HPLC method. This combination drug product is marketed by many of the pharmaceutical company but till now no method is available to determine the said drug in the routine quality control and stability sample analysis. It is mandatory to develop a stability indicating assay method for the unstable molecule like glimepiride and pioglitazone. Additionally to prove the selectivity of the method, glimepiride major degradation impurity of related compound $\mathrm{B}$ and related compound $\mathrm{C}$ was injected and estimated in the combination tablet. A single HPLC method is described in this paper for the simultaneous estimation of pioglitazone, glimepiride, glimepiride related compound B and related compound $\mathrm{C}$.

\section{EXPERIMENTAL}

\section{Materials and reagents}

Pharmaceutical grade standards of pioglitazone (5-(4-[2-(5-ethylpyridin2-yl)ethoxy]benzyl)thiazolidine-2,4-dione) and glimepiride (3-ethyl-4-methyl$N$-(4-[N-((1r,4r)-4- methylcyclohexylcarbamoyl) sulfamoyl] phenethyl)-2oxo-2,5-dihydro- $1 H$-pyrrole-1- carboxamide) were kindly supplied by $\mathrm{M} / \mathrm{S}$ Pharma Lab (Baddi, India). Glimepiride related compound B (3-Ethyl-4methyl-2-oxo-N-[2-(4- sulphamoylphenyl) ethyl]-2,3-dihydro-1H-pyrrole-1carboxamide ) and related compound C (Methyl [[4-[2-[[(3-Ethyl-4-methyl2-oxo-2,3-dihydro-1H-pyrrol-1-yl) carbonyl]amino]ethyl]phenyl]- sulphonyl] carbamate) were purchased from LGC standards (India).Chemical structures are shown in (Figure. 1). Commercially available combination tablets containing $15 \mathrm{mg}$ of pioglitazone, $2 \mathrm{mg}$ of glimepiride and $500 \mathrm{mg}$ of metformin $\mathrm{HCL}$
(PRICHEK GMP®-manufactured by Indoco Rem) were purchased. HPLC grade acetonitrile, analytical reagent grade potassium dihydrogen phosphate and ortho phosphoric acid were obtained from Rankem (India). Millipore water was used prepared from Milli-Q plus water purification system.

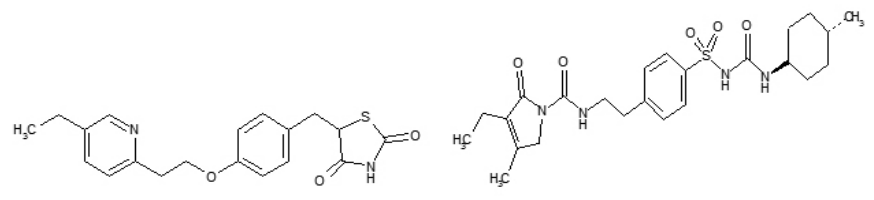

(a)

(b)

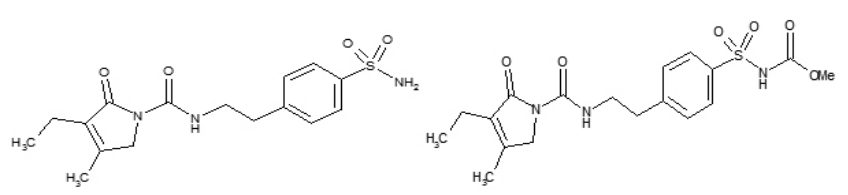

(c)

(d)

Figure. 1. Chemical structures of a) Pioglitazone b) Glimepiride c) Glimepiride related compound B d) Glimepiride related compound C.

\section{Chromatographic conditions}

The HPLC system was a Waters 2695 binary pump plus auto sampler and a 2996 photo diode array as well as 2487 UV detector.

The chromatographic column used for separation was a Zorbax cyano, 250 $\mathrm{x} 4.6 \mathrm{~mm}$ with 5 microns particles. Mobile phase contained solution- A and solution-B. Solution-A is $20 \mathrm{mmol} \mathrm{L}^{-1}$ potassium dihydrogen phosphate, $\mathrm{pH}$ adjusted to 3.2 using dilute ortho phosphoric acid. Solution-B is acetonitrile. The gradient program was as follows: (time $(\mathrm{min}) / \%$ solution B: $0.01 / 20,13 / 20$, $50 / 50,55 / 80,60 / 80,63 / 20,70 / 20$. Mixture of acetonitrile and water $(4: 1, \mathrm{v} / \mathrm{v})$ were used as sample diluent. The flow rate of the mobile phase was $0.8 \mathrm{~mL}$ $\mathrm{min}^{-1}$. The column temperature was maintained at ambient and the detection was monitored at a wavelength of $230 \mathrm{~nm}$. The desired LOQ value of impurities were achieved by using $25 \mu \mathrm{L}$ of injection volume

\section{System suitability solution}

Stock solutions of glimepiride related compound B, related compound $\mathrm{C}$ and glimepiride $\left(1000 \mu \mathrm{g} \mathrm{mL}^{-1}\right)$ were prepared by dissolving appropriate 
amounts. System suitability solutions of $0.2 \mu \mathrm{g} \mathrm{mL}^{-1}$ of related compound B and related compound $\mathrm{C}, 0.5 \mu \mathrm{g} \mathrm{mL}^{-1}$ of glimepiride were prepared from above stock solutions.

\section{Standard preparation}

A standard solution containing $750 \mu \mathrm{g} \mathrm{mL}-1$ of pioglitazone and 100 $\mu \mathrm{g} \mathrm{mL} \mathrm{L}^{-1}$ of glimepiride were prepared by dissolving appropriate amount of pioglitazone and glimepiride standard in diluent.

\section{Preparation of sample solution}

Twenty tablets were weighed and powdered with the help of mortar and pestle. An amount of powder tablets equivalent to $10 \mathrm{mg}$ glimepiride $(75 \mathrm{mg}$ of pioglitazone) were transferred to a $100 \mathrm{~mL}$ volumetric flask, $60 \mathrm{~mL}$ of diluent were added and kept on a rotatory shaker for $10 \mathrm{~min}$ to disperse the material completely, then sonicated for 10 min (during the sonication the bath temperature was maintained at $25^{\circ} \mathrm{C}$ ) and diluted to $100 \mathrm{~mL}$ with diluent. The concentration of pioglitazone and glimepiride was $750 \mu \mathrm{g} \mathrm{mL}^{-1}$ and $100 \mu \mathrm{g}$ $\mathrm{mL}^{-1}$. The resulting solution was centrifuged at $10000 \mathrm{rpm}$ for $5 \mathrm{~min}$. The supernatant solution was used for estimation of pioglitazone, glimepiride and glimepiride impurities.

\section{RESULTS AND DISCUSSIONS}

\section{Optimization of chromatographic method}

The HPLC method is optimized with a view to develop a stability indicating nature. A stability indicating method should accurately measure the active ingredients, without interference from degradation products and sample matrixes. Since pioglitazone and glimepiride is having a degradation nature gradient method is preferred over isocratic to get a complete degradation product as well as good resolution between close eluting compounds. To develop a method the initial trials were taken with pure drug of pioglitazone and glimepiride spiked with glimepiride related compound $\mathrm{B}$ and glimepiride related compound $\mathrm{C}$ was used a sample solution. Different buffer $\mathrm{pH}$ (2-7), different solvent system containing methanol and acetonitrile was tried. The reverse phase column chemistry of $\mathrm{C} 18$ is applied for preliminary trial. The good separation was achieved with gradient program contain solution A (phosphate buffer at $\mathrm{pH}$ 3.2) and solution B (acetonitrile) with a flow rate of $0.8 \mathrm{~mL} \mathrm{~min}{ }^{-1}$. To prove the stability indicating nature of the method all forced degradation samples were injected in the optimized conditions, but the peak purity of glimepiride and pioglitazone got failed due to some degradation compound elution at the same RT of the peak pioglitazone and glimepiride peak. To check this some gradient adjustment, column temperature and flow rate was tried, but these trials were not come up with the good result To rectify the problem, different column was tried initially C8 column was selected, but know compound itself got merged together in this column chemistry. While using phenyl column one degradation peak has come out from the glimepiride peak and glimepiride peak purity was found satisfied but pioglitazone peak purity was remain same. Finally the cyano column was used for the development; the main base degradation peak was come out with the more than 2.0 resolutions from pioglitazone peak. For our knowledge this is the first method was reported with the these many degradation peak is possible to form in the said combination drug product and all the degradation peak as well as known component was got very good resolution. All pioglitazone, glimepiride, glimepiride related compound $\mathrm{B}$ and related compound $\mathrm{C}$ was found adequate response at $230 \mathrm{~nm}$. In case of stressed sample, chromatogram was extracted with the entire range of $200-400 \mathrm{~nm}$ to check a new impurity at different wavelength but no extra peak was found except at $230 \mathrm{~nm}$ wavelength observed peaks. The required LOQ value of glimepiride related compound $\mathrm{B}$ and related compound $\mathrm{C}$ was found by using $100 \mu \mathrm{g} \mathrm{mL}^{-1}$ of glimepiride sample preparation with $25 \mu \mathrm{L}$ injection volume. During the development it was observed that the formation of related compound $\mathrm{B}$ is very fast and to get a consistent result the fresh sample preparation was prepared and used, the sonicator both temperature was maintained less than $25^{\circ} \mathrm{C}$ while preparing the sample solution. The critical close eluting impurity of glimepiride related compound $\mathrm{B}$ and related compound $\mathrm{C}$ was found better resolution than the current USP monograph glimepiride tablet method. System suitability chromatogram is shown in (Figure. 2). This is proving that in all the aspect the developed method is better than the till now reported methods.

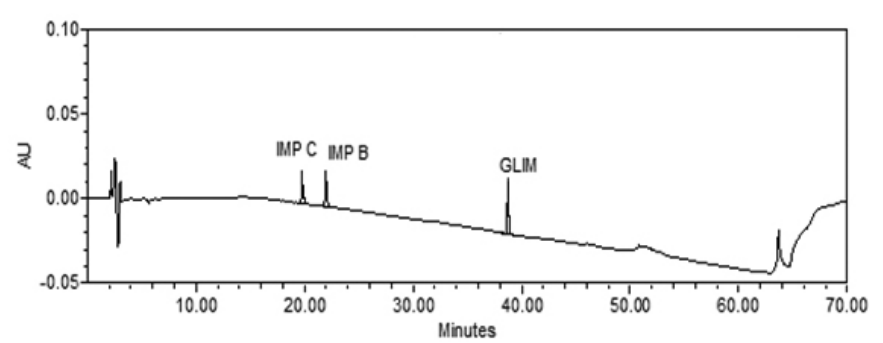

Figure. 2. System suitability chromatogram (contain glimepiride, glimepiride related compound B, glimepiride related compound C).

\section{Method validation}

The developed chromatographic method was validated for system suitability, selectivity, specificity, linearity, precision, accuracy, LOD, LOQ and robustness as per ICH guideline. ${ }^{15}$

System suitability

The observed retention times (RT) and relative retention times of the analytes are presented in Table 1 . The resolution between close eluting pair of glimepiride related compound $\mathrm{B}$ and glimepiride related compound $\mathrm{C}$ was set as the system suitability parameter $(>6.0)$. Also the RSD of the peak area of pioglitazone and glimepiride was calculated.

Table 1. System suitability results.

\begin{tabular}{|l|c|c|c|c|}
\hline Parameter & $\begin{array}{c}\text { Piogli- } \\
\text { tazone }\end{array}$ & $\begin{array}{c}\text { Gli- } \\
\text { mepi- } \\
\text { ride }\end{array}$ & $\begin{array}{c}\text { Glime- } \\
\text { piride } \\
\text { related } \\
\text { com- } \\
\text { pound B }\end{array}$ & $\begin{array}{c}\text { Glimepiride } \\
\text { related com- } \\
\text { pound C }\end{array}$ \\
\hline \% RSD & 1.1 & 1.3 & 4.1 & 3.2 \\
Retention time & 31.93 & 38.73 & 21.99 & 19.82 \\
Relative retention time & - & 1.00 & 0.57 & 0.51 \\
USP resolution & - & - & 6.50 & - \\
USP tailing factor & 1.01 & 0.99 & 1.22 & 1.13 \\
USP theoretical plates & 15011 & 18123 & 8012 & 7532 \\
\hline
\end{tabular}

\section{Specificity and selectivity}

Specificity of the developed method was assessed by performing forced degradation studies.

The specificity of the developed HPLC method was determined in the presence of it's degradation products and other sample matrix. Forced degradation studies were performed on tablet sample to provide an indication of the stability-indicating property and specificity of the proposed method. The sample solutions were subjected to acid and base hydrolysis (using 0.1N HCL and $0.1 \mathrm{~N} \mathrm{NaOH}$, respectively for $2 \mathrm{~h}$ ), to oxidation (using $3 \% \mathrm{H}_{2} \mathrm{O}_{2}$ for $2 \mathrm{~h}$ ) and to $\mathrm{UV}$ radiation (254nm for $48 \mathrm{~h}$ ).

When the drug was exposed to acid and peroxide condition minor degradation was observed but in case of base condition major degradation was observed. Related compound B was increased in all acid, base and peroxide stressed sample but related compound $\mathrm{C}$ was found only in peroxide condition. Chromatograms are shown in (Figure. 3). The said drugs are stable to the effect of photolysis, no degradation was observed. In all stressed samples peak purity were found within acceptable limit (purity angle is less than purity threshold) indicating the specificity of the method. Results are shown in (Table 2). To prove the selectivity of the method metformin hydrochloride was injected in the optimized method, no interference and overlap was found with the respect to pioglitazone, glimepiride and glimepiride impurities peaks. Chromatogram is shown in (Figure. 4). 
Table 2. Forced degradation results.

\begin{tabular}{|l|c|c|c|}
\hline Condition & Time & $\begin{array}{c}\text { \% Assay of } \\
\text { Glimepiride }\end{array}$ & $\begin{array}{c}\text { \% Assay of } \\
\text { Pioglitazone }\end{array}$ \\
\hline & & & \\
Unstressed sample & - & 99.2 & 99.0 \\
Acid hydrolysis (0.1N HCL) & 2h & 96.0 & 97.2 \\
Base hydrolysis (0.1N NaOH) & 2h & 91.9 & 82.3 \\
Oxidation (3\% H2O2) & 2h & 95.3 & 96.3 \\
Light(254nm) & $48 \mathrm{~h}$ & 100.2 & 99.2 \\
& & & \\
\hline
\end{tabular}

a)

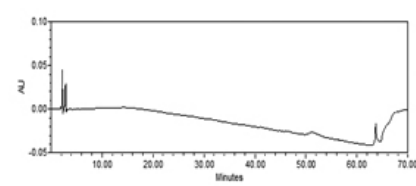

b)

c)

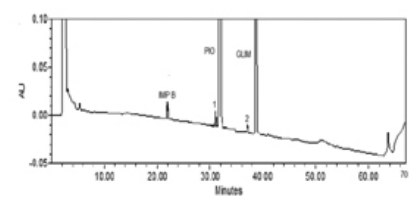

d)

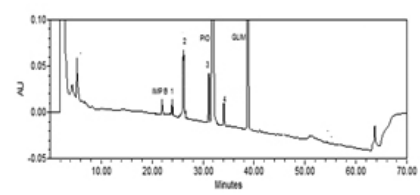

e)

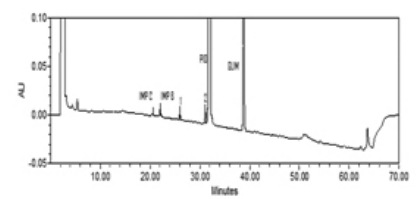

Figure 3. Chromatogram of a) Blank b) Unstressed Sample c) Acid hydrolysis sample d) Base hydrolysis sample e) Peroxide oxidation sample and Peaks 1.2.3 and 4 are degradent.

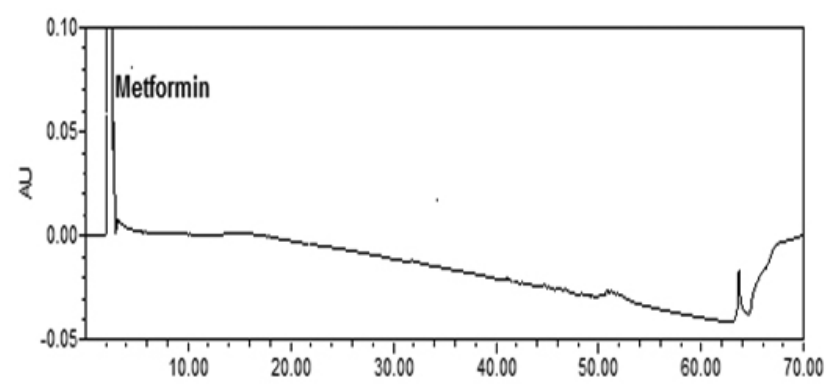

Figure 4. HPLC chromatogram of individual metformin hydrochloride injection.

\section{Limit of detection (LOD) and Limit of quantification ( $L O Q)$}

The LOD and LOQ were determined by measuring the magnitude of analytical background. In order to estimate the LOD and LOQ, serial dilution of glimepiride related compound B and related compound C solutions were used. The signal to noise ratio was determined. The signal to noise ratios of 3 and 10 were considered as LOD and LOQ respectively.

By injecting six preparations of the LOD and LOQ solutions of glimepiride related compound $\mathrm{B}$ and glimepiride related compound $\mathrm{C}$ was achieved $0.005 \%$ (i.e., $0.005 \mu \mathrm{g} \mathrm{mL}^{-1}$ ) and $0.02 \%$ (i.e., $0.02 \mu \mathrm{g} \mathrm{mL}^{-1}$ ) for $25 \mu \mathrm{L}$ injection volume. The precision at the LOQ concentrations for glimepiride related compound B and glimepiride related compound $\mathrm{C}$ were found less than $5.0 \%$

\section{Linearity}

Linearity of the assay method was evaluated by determining five concentration levels at three preparations from 50 to $150 \%$ of analyte concentration i.e., $750 \mu \mathrm{g} \mathrm{mL} \mathrm{m}^{-1}$ for pioglitazone and $100 \mu \mathrm{g} \mathrm{mL} \mathrm{m}^{-1}$ for glimepiride. Correlation was found more than 0.999 for both the compound. The linear equation obtained for glimepiride was $\mathrm{Y}=123012 \mathrm{x}+160007$ and for pioglitazone was $\mathrm{Y}=332706 \mathrm{x}-479991$.

For related compound $\mathrm{B}$ and related compound $\mathrm{C}$ six concentration levels from LOQ to $200 \%$ (LOQ, 25, 50, 100, 150 and 200\%) were prepared by diluting the impurity stock solution to the required concentrations. The correlation coefficient obtained was greater than 0.999 . The best-fit linear equation for related compound $\mathrm{B}$ was $\mathrm{y}=867436 \mathrm{x}-115.18$ and for related compound $\mathrm{C}$ was $\mathrm{y}=780417 \mathrm{x}-524.47$

Precision

The $\%$ RSD of six sample preparations (in single injection) assay values was 1.1 for pioglitazone and 0.9 for glimepiride. The average assay was found $98.2 \%$ for pioglitazone and $100.2 \%$ for glimepiride. The intermediate precision of the assay method was evaluated by different column, system, analyst and in different day, \% RSD's were within 2.0 for both pioglitazone and glimepiride, assay value was found between $98-102 \%$, confirming the ruggedness of the method.

The precision of the related compound $\mathrm{B}$ and related compound $\mathrm{C}$ was checked by injecting six individual preparation (in single injection) of (100 $\mu \mathrm{g}$ $\mathrm{mL}^{-1}$ ) glimepiride spiked with $0.2 \%$ of said impurity. The $\%$ RSD of related compound $\mathrm{C}$ and related compound $\mathrm{C}$ was found 3.2 and 2.9 respectively. In the intermediate precision the \% RSD for impurity was well within the limit $(<5.0)$.

\section{Accuracy}

The recovery of three sample preparations at five concentration levels $(50 \%, 75 \%, 100 \%, 125 \%$, and $150 \%$ of working concentration for pioglitazone, glimepiride and glimepiride impurities) were determined. The recovery of pioglitazone and glimepiride was obtained within acceptable range ( $98 \%$ to $102 \%)$. The recovery of related compound $\mathrm{B}$ and related compound $\mathrm{C}$ was ranged from $96.1 \%$ to $101.3 \%$ and $98.1 \%$ to $102.1 \%$ respectively.

\section{Robustness}

Chromatographic parameters of the method were intensely altered in order to measure the robustness of the method. The system suitability parameters as well as the recovery for the main ingredients in the sample solution were examined. The parameters altered were the flow rate $\left( \pm 0.1 \mathrm{~mL} \mathrm{~min}^{-1}\right)$, the buffer's $\mathrm{pH}( \pm 0.2)$ and the organic composition $( \pm 5 \%)$ in the mobile phase.

The results obtained from the deliberate changes were well within the limit. The adequate resolution obtained between related compound $\mathrm{B}$ and related compound $\mathrm{C}$ in all the changes $(>5.0)$. The assay value of pioglitatone and glimepiride was obtained between $98 \%$ to $102 \%$ showing the robustness of the method.

\section{Application of the developed method to commercial tablets}

In order to evaluate the application of method, commercial preparations (PRICHEK GMP®-manufactured by Indoco Rem- Tablets containing $15 \mathrm{mg}$ of pioglitazone, $2 \mathrm{mg}$ of glimepiride and $500 \mathrm{mg}$ of metformin HCL) were analysed. The samples were prepared six times as described above and the content of pioglitazone, glimepiride, glimepiride related compound B and glimepiride related compound $\mathrm{C}$ was calculated. The average assay value of pioglitazone, glimepiride and glimepiride related compound B was found $98.2 \%, 100.1 \%$, and $0.07 \%$ respectively. Glimepiride related compound $\mathrm{C}$ was not detected in the analysed commercial sample.

\section{CONCLUSIONS}

A single reversed phase stability indicating RP-HPLC method has been established for simultaneous estimation of pioglitazone, glimepiride and glimepiride related compound $\mathrm{B}$ and related compound $\mathrm{C}$ from combination drug product. The method was fully validated and the data found to be satisfactory for all the method validation parameters tested. The developed method can be conveniently used by a quality control department to determine the said compound in routine analysis and commercial sample purity check.

\section{ACKNOWLEDGEMENTS}

The authors would like to thank M/S Pharma Lab (Baddi, India) for providing the standards. 


\section{REFERENCES}

1. http://en.wikipedia.org/wiki/Glimepiride, accessed in March 17, 2011.

2. http://en.wikipedia.org/wiki/Pioglitazone, accessed in March 17, 2011

3. http://www.uspnf.com/uspnf/pub/index? usp=33\&nf=28\&s=2\&officialOn =February\%201,\%202011, USP online, accessed in March 17, 2011.

4. D. B. Wanjari, N. J. Gaikwad, J. Pharm. Sci. 67, 253, (2005).

5. Rudy Bonfilio, Magali B. de Araújo, R. N. Hérida, Salgado, J. Braz. Chem. Soc. 22, 292, (2011)

6. A. K. Mubeen, S. Sukumar, V. Santosh, B. Atul, Shankar Kumar. J. Pharm. Biomed. Anal. 39, 928, (2005).

7. G. Bansal, M. Singh, K. C. Jindal, S. J. Singh, J. Pharm. Biomed. Anal. 48, 788, (2008)

8. Petra Kova íková, Ji i Klime, Ji íohnal, Lucie Tisovská, J. Pharm. Biomed. Anal. 36, 205, (2004).
9. K. Ramulu, T. Thilak Kumar, S. Radha Krishna, R. Vasudev, M. Kaviraj, B. M. Rao, N. Someswara Rao, Pharmazie 65, 162, (2010).

10. Smita Sharma, Mukesh Chandra Sharma, S. C. Chaturvedi, J. Opteo, Biomed. Mate. 1, 17, (2010).

11. A. S. Atul, J. S. Sanjay, J. Planar. Chromatogr. 22, 191, (2009).

12. D. Jain, S. Jain, M. J. Amin, J. Chromatogr. Sci. 46, 501, (2008).

13. K. S. Lakshmi, T. Rajesh, S. Sharma, S. Lakshmi, Der Pharma Chemica. 1, 238, (2009).

14. A. Karthik, G. Subramanian, C. Mallikarjuna Rao, Krishna Murthy Bhat, A. Ranjithkumar,

P. Musmade, M. Surulivelrajan, K. Karthikeyan, N. Udupa, Pak. J. Pharm. Sci. 21, 421, (2008).

15. http://private.ich.org/cache/compo/363-272-1.html, accessed March 17, 2011. 